\title{
COMPARAÇÃO DE QUATRO EXTRATORES DE FÓSFORO DE SOLOS $\left(^{1}\right)$
}

\begin{abstract}
BERNARDO VAN RAIJ (2), CELI TEIXEIRA FEITOSA (2), Seção de Fertilidade do Solo e Nutriçāo de Plantas, e NELSON MACHADO DA SILVA (2), Seção de Algodão, Instituto Agronômico.
\end{abstract}

\section{RESUMO}

E apresentado um estudo comparativo de quatro métodos de extração de fósforo de solos: a) IAC, baseado na extração de $5 \mathrm{~cm}^{3}$ de terra com $50 \mathrm{ml}$ de $\mathrm{H}_{2} \mathrm{SO}_{4} 0,05 \mathrm{~N}$; b) Bray I modificado, baseado na extração de $2,5 \mathrm{~cm}^{3}$ de terra com $50 \mathrm{ml}$ de solução $0,03 \mathrm{~N}$ em $\mathrm{NH}_{4} \mathrm{~F}$ e $0,025 \mathrm{~N}$ em $\mathrm{HCl}$; c) Olsen, baseado na extração de $2,5 \mathrm{~cm}^{3} \mathrm{de}$ terra com $50 \mathrm{ml}$ de $\mathrm{NaHCO}, 0,5 \mathrm{~N}$ a $\mathrm{pH} 8,5$ e d) resina, baseado na extração de $5 \mathrm{~cm}^{3}$ de terra com $2,5 \mathrm{~cm}^{3}$ de resina trocadora de anions, com agitação por duas horas em suspensão aquosa. Para comparar os métodos determinou-se, para cada um deles, a correlacão entre os teores de fósforo nos solos e os resultados de respostas à adubação fosfatada em ensaios de campo, de 16 ensaios de milho e 16 de algodão. Para as duas culturas em conjunto, os valores absolutos dos coeficientes de correlaçāo, para os quatro métodos, foram: a) 0,683 ; b) 0,650 ; c) 0,391 e d) 0,802 , indicando a superioridade do método da resina.

\section{INTRODUÇÃO}

No Brasil atualmente são usados, nos laboratórios de rotina de análise de solo, dois métodos para a análise de fósforo em solos, que fornecem praticamente os mesmos resultados. No método IAC,

(i) Trabalho realizado dentro do projeto "Avaliação Agronómica de Fosfatos Brasileiros", com recursos da FINEP. Apresentado no XVIII Congresso Brasileiro de Ciência do Solo, realizado em Salvador (BA), 30 de agosto-06 de setembro de 1981. Recebido para publicação a 24 de maio de 1982.

(í) Com bolsa de suplementação do CNPq. 
utilizado em São Paulo, o extrator é o ácido sulfúrico 0,05N (3), enquanto no Mehlich ou Carolina do Norte, adotado nos demais Estados, o extrator é uma mistura $0,05 \mathrm{~N}$ em ácido clorídrico e $0,025 \mathrm{~N}$ em ácido sulfúrico (7).

Esses métodos apresentam grande vantagem para uso rotineiro, principalmente porque permitem obter extratos límpidos, que decantam facilmente, dispensando a filtragem das suspensões de solos. Apresentam, porém, dois graves defeitos: o primeiro manifesta-se em certos solos argilosos, com destaque para latossolos roxos, onde a extração de fósforo é baixa, mesmo naqueles bem supridos do nutriente. $\mathrm{O}$ outro defeito manifesta-se em solos que contêm resíduos inalterados de fosfatos naturais, para os quais os resultados de fósforo são muito elevados $(5,9,10)$.

Esses dois problemas, que trazem considerável insegurança para análise de solo, praticamente condenam os extratores de fósforc atualmente em uso.

Opções para métodos de fósforo existem às dezenas. Contudo, se for considerada a exigência de não-dissolução, no processo de extração do fósforo do solo, de formas não disponiveis ou de resíduos de fosfato naturais porventura existentes nos solos, a escolha se reduz a poucas alternativas.

Em recente revisão bibliográfica sobre métodos de análise de fósforo, feita por RAIJ (9), ficou demonstrado que o método mais eficiente para fósforo, em uma variedade de condições, é o baseado na extração do elemento por uma resina trocadora de anions, mesmo em solo tratado recentemente com fosfatos naturais (10).

$\mathrm{Na}$ revisão, destacou-se em segundo lugar o método do bicarbonato de sódio $0,5 \mathrm{~N}$ a $\mathrm{pH} 8,5$, que também não extrai fósforo de resíduos de fosfatos naturais de solos (5). Um terceiro método, eficaz para fósforo e que também não dissolve fosfatos naturais, é o que utiliza a extração com solução de ácido clorídrico $0,025 \mathrm{~N}$ em fluoreto de amônio a $0,3 \mathrm{~N}(\mathbf{1 0})$.

Neste trabalho é apresentado um estudo comparativo de quatro métodos de extração de fósforo no solo, correlacionando-se os resultados de análise de solo com resultados experimentais de campo de ensaios de milho e algodão.

\section{MATERIAL E MÉTODOS}

Foram aproveitados resultados de milho e algodão, bem como amostras compostas dos solos retiradas das áreas dos ensaios antes de sua instalação. Os de milho foram instalados em diversos solos 
importantes do Estado de São Paulo, sendo seus resultados apresentados em outro trabalho (11). Os ensaios de algodão, instalados principalmente em latossolo roxo e latossolo vermelho-escuro textura média, serão objeto de publicação futura. Para este trabalho, foram empregadas as amostras dos solos e alguns resultados experimentais relacionados a fósforo.

No caso dos resultados experimentais, partiu-se de curvas de resposta, calculadas para as doses de $0,25,50$ e $75 \mathrm{~kg} / \mathrm{ha}$ de $\mathrm{P}_{2} \mathrm{O}_{5}$, para algodão, e de $0,40,80$ e 120, para um grupo de ensaios de milho, e 0 , 30,60 e $90 \mathrm{~kg} / \mathrm{ha}$ de $\mathrm{P}_{2} \mathrm{O}_{\overline{5}}$ para outro grupo, adubações essas aplicadas no sulco de plantio. Além de fósforo, foram feitas aplicações de calcário, nitrogênio e potássio. Em cada caso, determinou-se a regressão entre níveis de fósforo aplicado e as produções, ajustando a equação de $2 .^{\circ}$ grau. Determinou-se para cada ensaio a produção para a dose 0 e a produção máxima. Quando esta se situou além da dose máxima testada, foi considerada como a correspondente à maior dose testada. Ensaios com efeito depressivo de fósforo, com "pontos de sela" ou com coeficientes de variação acima de $20 \%$, não foram utilizados, pois o objetivo deste trabalho foi apenas comparar métodos para fósforo, e, para isso, săo necessários resultados experimentais que reflitam da melhor maneira possível o efeito do fósforo, com um mínimo de influências estranhas. dimentos :

A extração do fósforo foi feita utilizando os seguintes proce-

a) Extração com solução de $\mathrm{H}_{2} \mathrm{SO}_{4}$ 0,05N. Trata-se de um método em uso no Estado de São Paulo há várias décadas (2, 3) e descrito recentemente por RAIJ \& ZULLO (12). Para a extração, $5 \mathrm{~cm}^{3}$ de terra foram agitados por cinco minutos com $50 \mathrm{ml}$ de solução $\mathrm{H}_{2} \mathrm{SO}_{4}$ $0,05 \mathrm{~N}$. A suspensão foi deixada decantar, e retiradas alíquotas para análise.

b) Extração com solução de $\mathrm{NH}_{4} \mathrm{~F} 0,03 \mathrm{~N}+\mathrm{HCl} 0,025 \mathrm{~N} . \mathrm{O}$ método original é conhecido como Bray I (1). A extração foi feita agitando $2,5 \mathrm{~cm}^{3}$ de terra com $50 \mathrm{ml}$ de solução de $\mathrm{NH}_{4} \mathrm{~F} 0,03 \mathrm{~N}+\mathrm{HCl} 0,025 \mathrm{~N}$, agitando cinco minutos e filtrando através de papel de filtro Whatman n. ${ }^{\circ} 42$.

c) Extração com solução de $\mathrm{NaHCO}_{3}, 0,5 \mathrm{~N}$ a pH 8,5. O método original é de OLSEN (8). A extração foi feita agitando $2,5 \mathrm{~cm}^{3}$ de terra com $50 \mathrm{ml}$ de solução de $\mathrm{NaHCO}_{3} 0,5 \mathrm{~N}$ a pH 8,5 por trinta minutos e filtrando através de papel de filtro Whatman n. ${ }^{\circ} 42$.

d) Extração pela resina trocadora de aníons. Adaptou-se o método da resina trocadora de aníons saturada de bicarbonato, descrita por SIBBESEN (13). A resina usada foi a Amberlite IRA-400, aniônica base forte, com $2,5 \mathrm{~cm}^{3}$ em saquinhos de malha de poliéster. A resina 
foi pré-condicionada com solução de $\mathrm{KH}_{2} \mathrm{PO}_{4} 0,5 \mathrm{~N}$ e lavagens com água e $\mathrm{HCl} 0,5 \mathrm{~N}$. Quando não em uso, a resina foi sempre guardada em solução de $\mathrm{HCl} 0,1 \mathrm{~N}$. Antes de usar, a resina foi tratada com solução de $\mathrm{NaHCO}_{3}$ $0,5 \mathrm{~N}$ por quinze minutos, na base de $20 \mathrm{ml}$ por saquinho de resina e, em seguida, lavada com água destilada. Esse tratamento fó aplicado três vezes, sempre imediatamente antes de utilizar a resina. Para a extraçāo, colocaram-se em frasco erlenmeyer $5 \mathrm{~cm}^{3}$ de terra, $50 \mathrm{ml}$ de água destilada e um saquinho de resina saturada com bicarbonato, agitando-se por duas horas e lavando-se o saquinho de resina com água destilada. Para a extração do fósforo da resina, o saquinho foi colocado em $50 \mathrm{ml}$ de $\mathrm{HCl} 0,5 \mathrm{~N}$. Após trinta minutos de contacto e mais trinta de agitação, separou-se o saquinho da resina, guardando-se o extrato para a determinação de fósforo.

Essa determinação foi feita pelo método colorimétrico, descrito por MURPHY \& RILEY (6). Preparou-se uma solução estoque ácida de molibdato, dissolvendo $20 \mathrm{~g}$ de molibdato de amônio $\left(\mathrm{NH}_{4}\right) 6 \mathrm{Mo}_{7} \mathrm{O}_{24} 4 \mathrm{H}_{2} \mathrm{O}$, em $200 \mathrm{ml}$ de água destilada, com ligeiro aquecimento que não ultrapassou $60^{\circ} \mathrm{C}$. Nesta solução, dissolveu-se $0,70 \mathrm{~g}$ de tartarato de antimônio e potássio, e adicionaram-se $320 \mathrm{ml}$ de ácido sulfúrico concentrado p. a., com resfriamento sob água corrente. A solução foi resfriada, completada a um litro e homogeneizada. Esta solução, acondicionada em frasco escuro e sob refrigeração, serviu para preparar soluções diluídas.

Para as determinações de fósforo, foram preparadas, pouco antes de seu uso, soluçōes diluídas de molibdato contendo, em um litro, as seguintes quantidades da solução estoque ácida de molibdato e de ácido ascórbico, respectivamente, para os quatro métodos de fósforo: a) $60 \mathrm{ml} \mathrm{e} 1,5 \mathrm{~g}$; b ) $50 \mathrm{ml}$ e $1,5 \mathrm{~g}$; c) $80 \mathrm{ml} \mathrm{e} 2 \mathrm{~g}$; d) $40 \mathrm{ml}$ e $1 \mathrm{~g}$. Para as determinaçōes de fósforo, as quantidades de extrato e soluçóes diluídas de molibdato foram, respectivamente: a) $5 \mathrm{ml} \mathrm{e} 10 \mathrm{ml}$; b) $5 \mathrm{ml}$ e $20 \mathrm{ml}$; c) $5 \mathrm{ml}$ e $10 \mathrm{ml}$; d) $5 \mathrm{ml}$ e $20 \mathrm{ml}$. As leituras foram feitas em espectrofotômetro a $885 \mathrm{~nm}$, após dez minutos de contacto, nos três primeiros casos, e trinta minutos no método da resina. As leituras podem também ser feitas a $660 \mathrm{~nm}$. As curvas padrões foram preparadas nas soluçōes extratoras, dentro das condições de determinação descritas e para concentraçōes finais máximas de até $0,8 \mathrm{ppm}$ de $\mathrm{P}$.

Com os resultados de fósforo e os dados de produção, foram estabelecidas as correlações entre teores no solo e a resposta à adubação fosfatada, expressas em termos de produção relativa, que é dada por:

$$
\text { Produção relativa }=\frac{\text { Produção sem fósforo } \times 100}{\text { Produção máxima com fósforo }}
$$

Ajustou-se aos dados a equação $\mathrm{Y}=\mathrm{a}+\mathrm{b} / \mathrm{X}$. 


\section{RESULTADOS E DISCUSSÃO}

No quadro 1, são apresentados os resultados de análise de solo e produções calculadas dos ensaios de milho. No quadro 2, os mesmos resultados, referentes a algodão. Os solos escolhidos apresentam bastante variação em matéria orgânica, o que implica, em parte, também em variação na textura.

Nas figuras 1, 2, 3 e 4 são apresentadas as regressões entre as produções relativas e os teores de fósforo no solo.

$\mathrm{O}$ método do ácido sulfúrico $0,05 \mathrm{~N}$ apresenta os pontos acumulados em uma pequena faixa abaixo de $10 \mu \mathrm{g} / \mathrm{cm}^{3}$ de P (Figura 1). Da mesma forma, a extração com bicarbonato de sódio (Figura 2) nāo melhorou muito a situação, embora os pontos se distribuíssem em uma faixa maior. A extração com fluoreto de amônio em ácido clorídrico (Figura 3) leva a uma distribuição razoável, mas ainda mantendo certa aglomeração dos pontos experimentais. Já o método da resina (Figura 4) proporcionou os melhores coeficientes de correlação e uma distribuição bem razoável dos dados.

Como já exposto, nos solos em que houve uso de fosfatos naturais, o extrator $\mathrm{H}_{2} \mathrm{SO}_{4} 0,05 \mathrm{~N}$ deve ser condenado, já tendo sido demonstrada sua ineficiência em vários trabalhos, dentre eles os de FEITOSA \& RAIJ (5) e RAIJ \& DIEST (10). A correlação com a resposta às culturas não favorece o método (Figura 1), ficando apenas como um aspecto altamente positivo a facilidade de uso.

Os extratores Olsen (Figura 2) e Bray I (Figura 3) necessitam filtragem para a sua execução. Além disso, fornecem extratos muito amarelos, o que às vezes interfere nos resultados. Como no caso do ácido sulfúrico, são extratores absolutamente empíricos, específicos para determinadas formas de fósforo e não dissolvendo outras, o que pode não coincidir com aquelas mais disponíveis do elemento no solo.

O método da resina apresentou a melhor correlação com a resposta das culturas a fósforo aplicado, confirmando a tendência já observada em uma revisão feita na literatura mundial sobre extratores de fósforo de solos (10).

Um dos inconvenientes da resina na extração de fósforo é o fato de ser um método trabalhoso. Contudo, deve-se considerar que, além da melhor correlação com respostas à adubação fosfatada, apresenta analogia com a extração da planta muito superior aos outros métodos. Considerando-se, também, o aspecto positivo de não incluir nenhum agente químico de ação específica sobre os fosfatos do solo, valem esforços para sua utilização. 


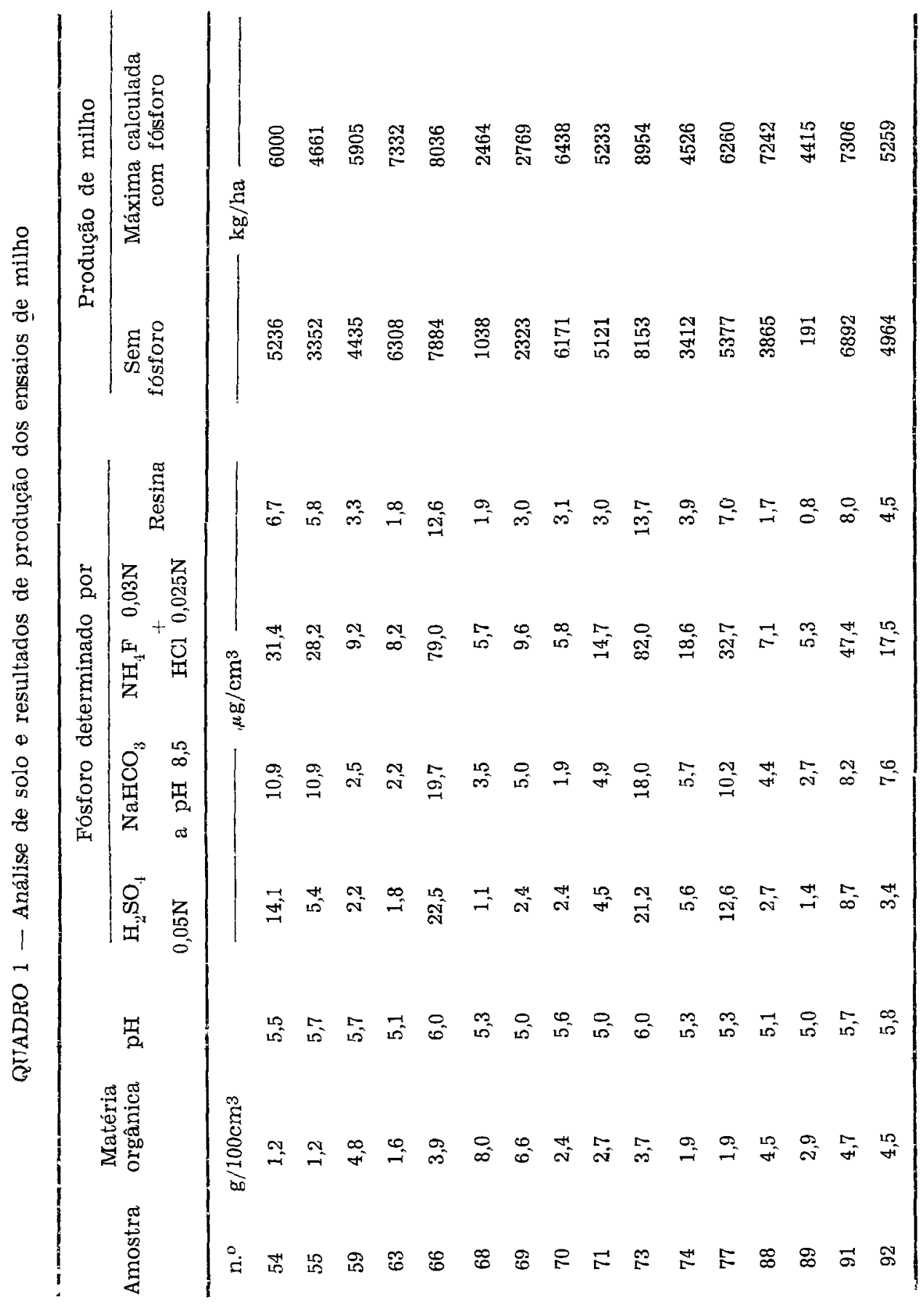




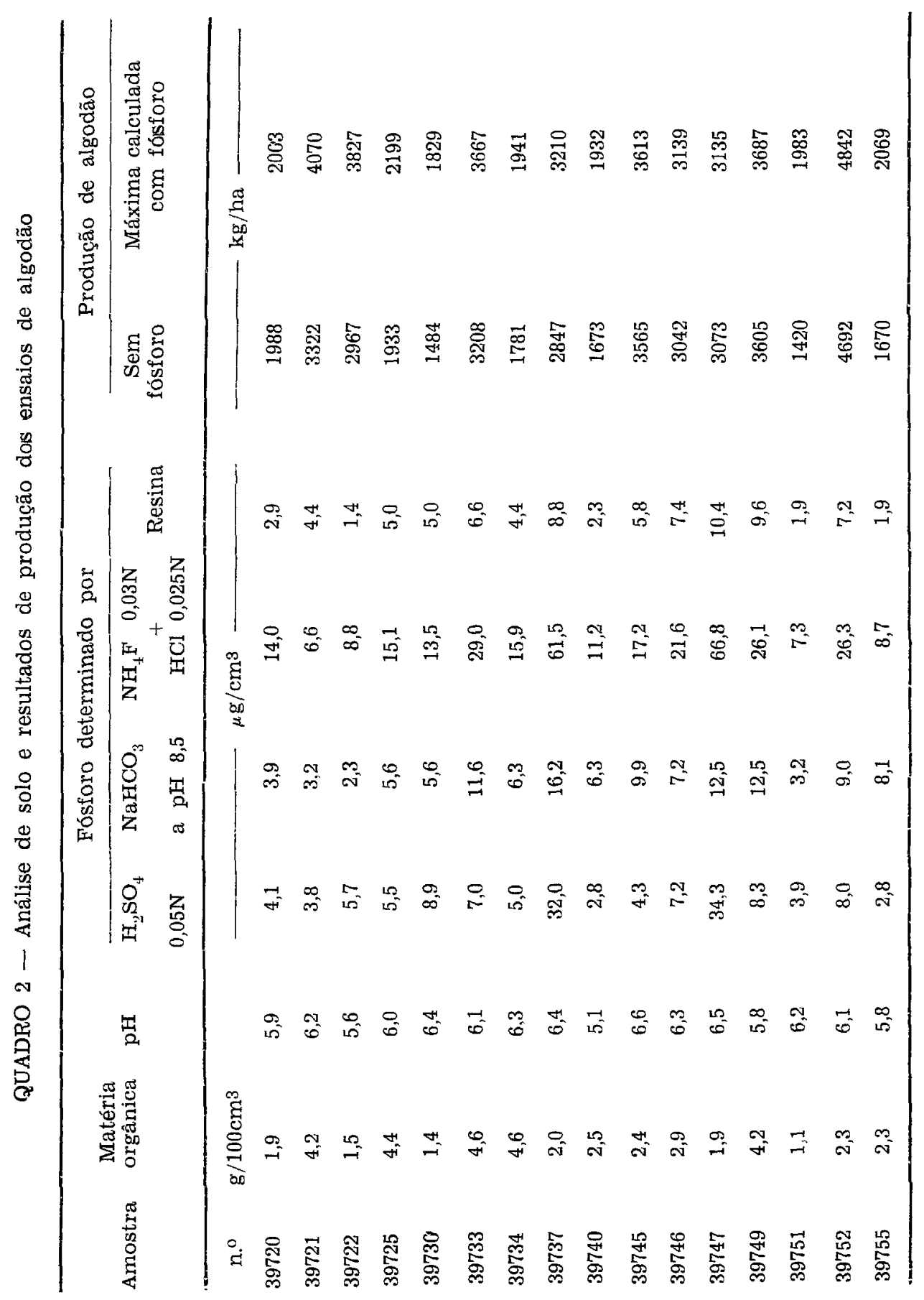




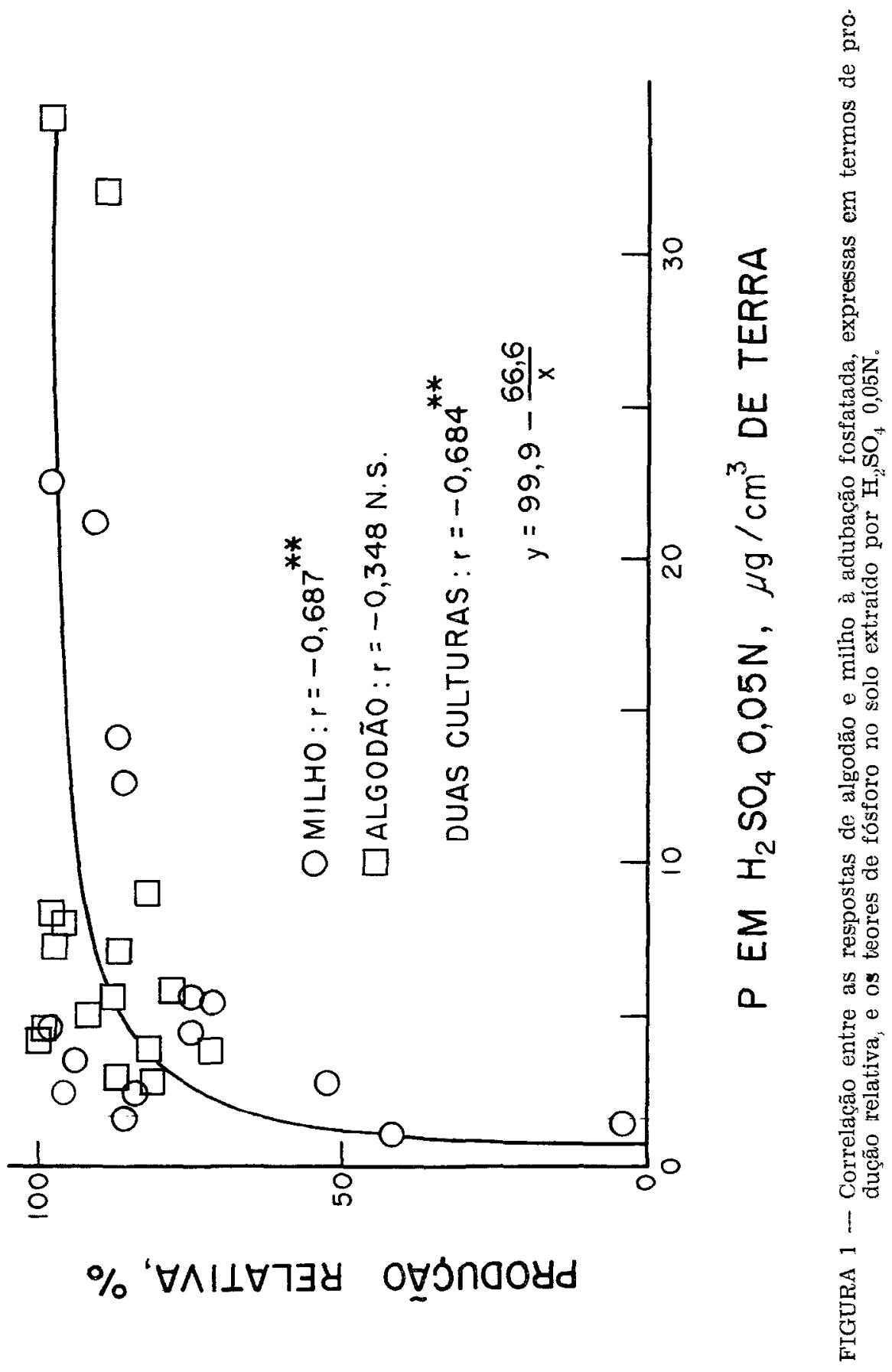




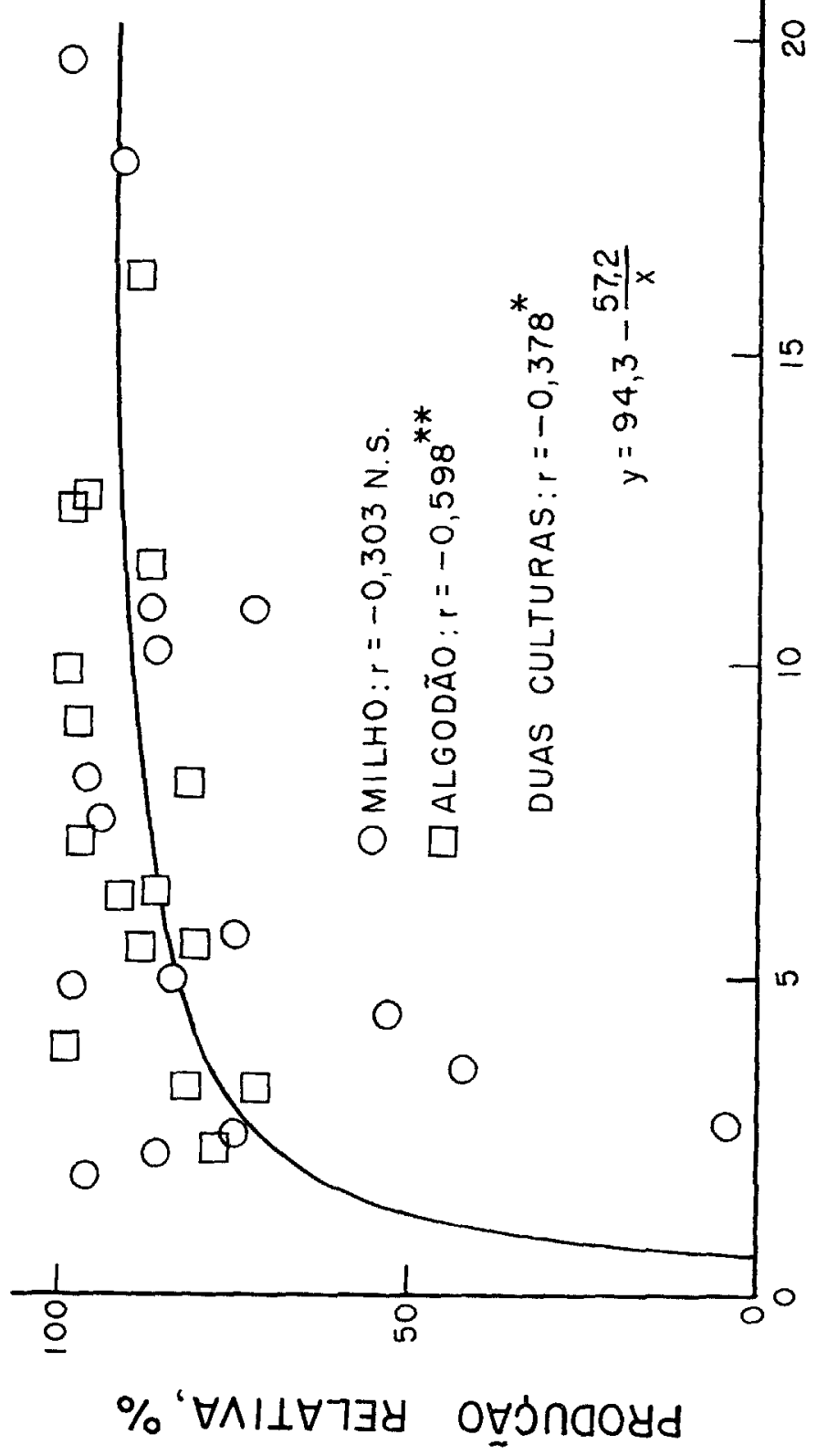

究

$\stackrel{9}{8}$

on

声

空

告

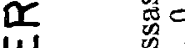

W

w

M 要要

'E

$\checkmark \quad 0$

on

- 泀号

10 융

$\infty \quad \omega$

I $\quad$ 要

< घㅇํㅇ

$Z$ 雾역

n कृ유

m

0 웅.

I 栗

ㄴ

$\sum$ แू है

山

a

要 

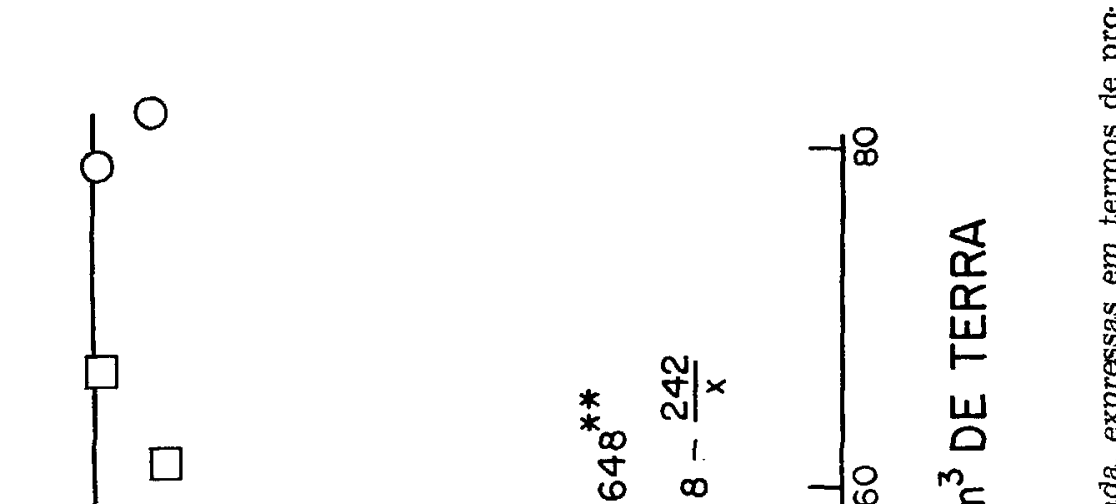

$\dot{\circ}$

忘

$-18$

웅

क्ष

\&

敢范

要:

压

要

$\square$

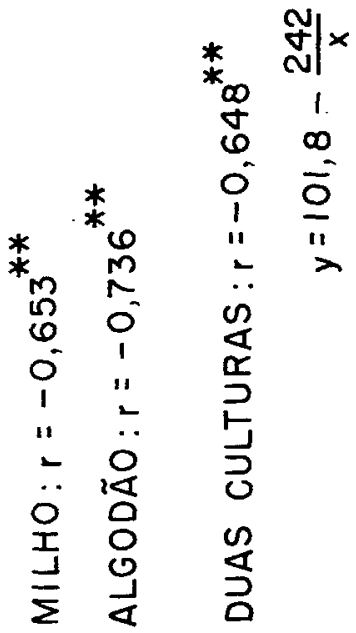

0

80

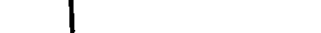




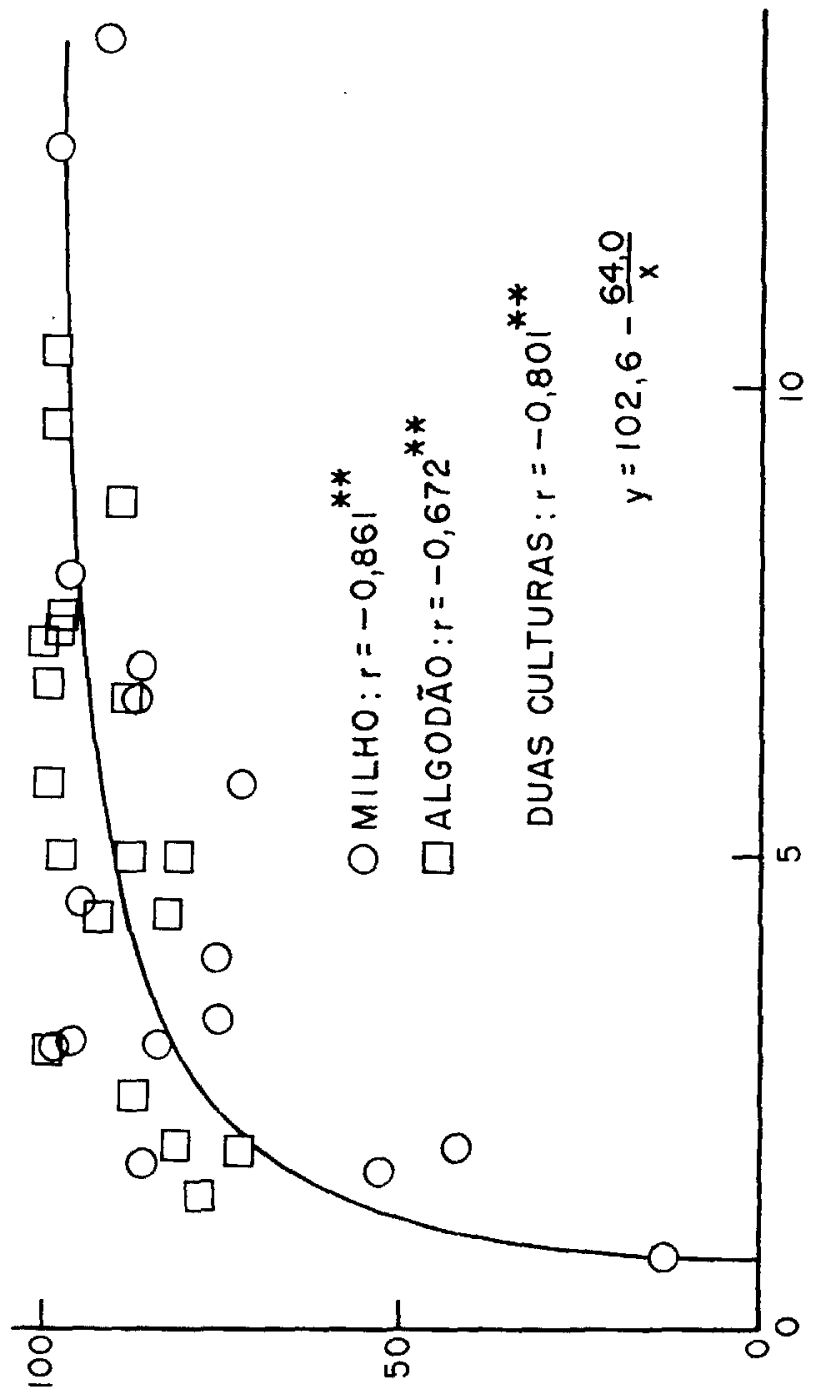

$$
\% \text { * } \forall 1 \perp \forall 7 \exists y \text { oํำooyd }
$$

Q

a

$\frac{1}{0}$

융 
Neste trabalho, optou-se por um tempo de extração com a resina de duas horas apenas, em contraposição com o mais comumente usado, de 18 horas (COOKE \& HISLOP, 4, e SIBBESEN, 13). Um tempo de duas horas de agitação é conveniente, para um iaboratório de rotina. Tempos de agitação maiores levam a extrações mais elevadas do fósforo, o que tem vantagens do ponto de vista analítico. Existem, além deste, outros aspectos relacionados ao método da resina que necessitam melhores estudos.

\section{SUMMARY \\ COMPARISON OF FOUR EXTRACTORS OF SOIL PHOSPHORUS}

A comparative study of four methods used for the extraction of soil phos. phorus, is presented. The methods were: a) IAC method, based on the extraction of $5 \mathrm{~cm}^{3}$ of soil with $50 \mathrm{ml}$ of $0.65 \mathrm{~N} \mathrm{H}_{2} \mathrm{SO}_{4}$; b) a modified Bray I method, based on the extraction of $2.5 \mathrm{~cm}^{3}$ of scil with $50 \mathrm{ml}$ of a solution $0.03 \mathrm{~N}$ in $\mathrm{NH}_{4} \mathrm{~F}$ and $.0 .025 \mathrm{~N}$ in $\mathrm{HCl}$; c) Olsen's method, based on the extraction of $2.5 \mathrm{~cm}^{3}$ of soil with $50 \mathrm{ml}$ of $0.5 \mathrm{~N} \mathrm{NaHCO}_{3}$ solution at $\mathrm{pH} 8.5 ; \mathrm{d}$ ) an anion exchange resin method based on the extraction of $5 \mathrm{~cm}^{3}$ of soil with $2.5 \mathrm{~cm}^{3}$ of an anion exchange resin contained in a polyester netting bag, by shaking in $50 \mathrm{ml}$ water. For each method, the correlation coefficients between soil phosphorus and the response to phospho. rus fertilization of 16 field experiments of cotton and 16 field experiments of corn were, respectively, $0.683,0.650,0.391$ and 0.802 , indicating the superiority of the anion-exchange resin method for the asseissment of soil phosphorus availability.

\section{REFERENCIAS BIBLIOGRÁFICAS}

1. BRAY, R. H. \& KURTZ, L. 'T, Determination of total, organic, and available forms of phosphorus in soils. Soil Science, 59:39-45, 1945.

2. CATANI, R. A.; GALLO, J. R.; GARGANTINI, H. Amostragem de solo, métodos de antílises, interpretação e indicaçōes gerais para fins de fertilidade. Campinàs, Instituto Agronômico, 1955. 29p. (Boletim, 69)

3. \& GARGANTINI, H. Extração de fósforo do solo pelo método Neubauer e por métodos químicos. Bragantia, Campinas, 13:55-62, 1954.

4. COOKE, I. \& HISLOP, J. Use of anion exchange-resin for the assesisment of available soil phosphate. Soil Science, 96:308-311, 1963.

5. FEITOSA, C. T. \& RAIJ, B. van. Influência da natureza de fosfatados aplicados a dois solos no fósforo solúvel em extratores químicos e disponível para trigo e mitho. In: CONGRESSO BRASILEIRO DE CIENCIA DO SOLO, 15., Campinas, 1976. Anais. Campinas, Sociedade Brasileira de Ciência do Solo, 1976. p.215-220.

5. MURPHY, J. \& RILEY, J. P. A modified single solution method for the determination of phosphate in natural waters. Analytica Chimica Acta, $27: 31-36,1962$.

7. NELSON, W. L.; MEHLICH, A.; WINTERS, E. The development and use of scil tests for phosphorus availability. In: PIERRE, W. H., \& NORMAN, A. G., eds. Soil and fertilizer phosphorus in crop nutrition. New York, Academic Press, 1953. p.153-188. (Agronomy, v.4) 
8. OLSEN, S. R. Inorganic phosphorus in alkaline and calcareous soils. In. PIERRE, W. H. \& NORIMAN, A. G. eds. Soil and fertilizer phosphorus in crop nutrition. New York, Academic Press, 1953. p.89-122. (Agronomy, v.4)

9. RAIJ, B. van. Seleção de métodos de laboratório para avaliar a disponibi lidade de fósforo em solos. Revista Brasileira de Ciência do Solo, Cam. pinas, $2: 19,1978$.

10. \& DIEST, A. van. Phosphate supplying power of rock phosphates in an oxisol. Plant and. Soil, 55:97-104, 1980.

11. - FEITOSA, C. T.; CANTARELLA, H.; CAMARGO, A. P.; DECHEN A. R.; ALVES, S.; SORDI, G.; VEIGA, A. A.; CAMPANA, M. P.; PETINELLI, A. O emprego da análise de solo para discriminar respostas à adubação para a cultura do milho. Bragantia, Campinas, 41:57-75, 1982.

12. \& ZULLO, M. A. T. Métodos de análise de solos para fíns de fertilidade. Campinas, Instituto Agronômico, 1977. 16p. (Circular, 63)

13. SIBBESEN, E. A simple ion-exchange resin procedure for extracting plant available elements from soil Plant and Soil, 46:665.669, 1977. 